A STUDY ON USE OF POLYPROPYLENE (PP) AND PP

COMPOSITES IN THE MANUFACTURE OF CASTOR WHEELS AND

THEIR EFFECT, ON PROCESSING, DYNAMIC AND STATIC

CHARACTERISTICS

BY

RANATUNGA RAMANAYAKA MUDIYANSELAGE SISIRA

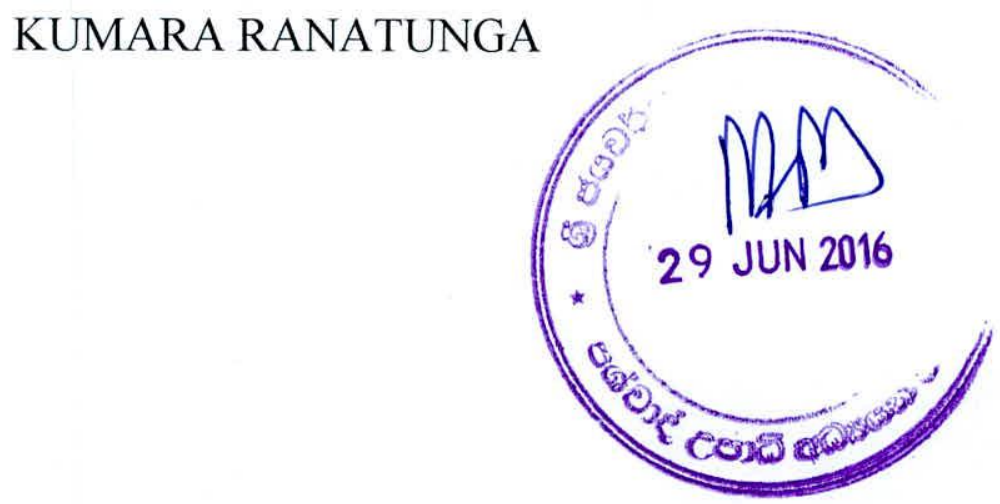

Thesis submitted to the University of Sri Jayewardenepura for the award of the Degree of Doctor of Philosophy in Chemistry on

September 2015 


\section{DECLARATION BY THE CANDIDATE}

The work described in this thesis was carried out by me under the supervisions of Prof. L. Karunanayake, Senior lecturer, Department of Chemistry, University of Jayewardenepura, Dr. S. Walpalage Senior Lecturer, Department of Chemical Engineering, University of Moratuwa and Dr. N. C. Ganegoda, Senior Lecturer, Department of Mathematics, University of Jayewardenepura and a report on this has not been submitted in whole or in part to any university or any other institution for another Degree/Diploma

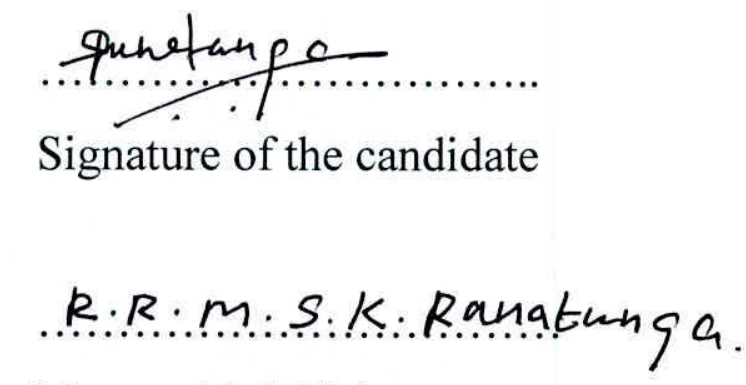

Name with initials 


\section{CERTIFICATION OF SUPERVISORS}

We certify that the candidate has incorporated all corrections, additions and amendments recommended by the examiners

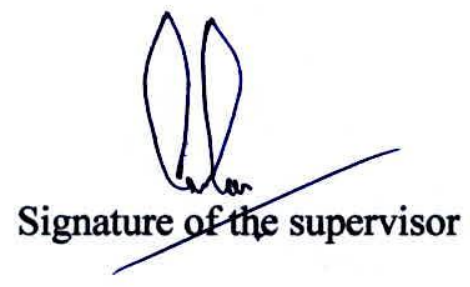

Name with initials

Name and address

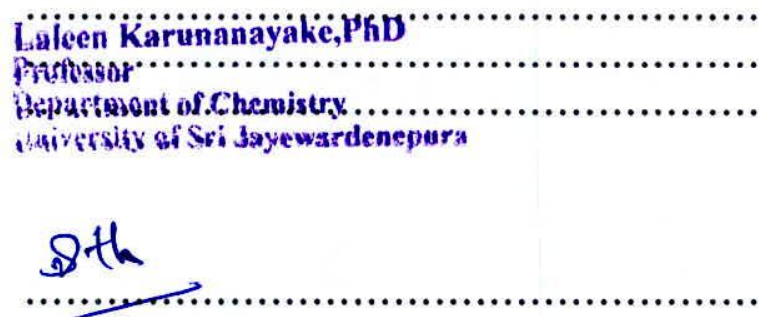

Signature of the supervisor

Name with initials

Name and address

Dr. Shantha Walpalage B.St: Eng; PhD (UK); 'C:Eng:; MPE(SL)

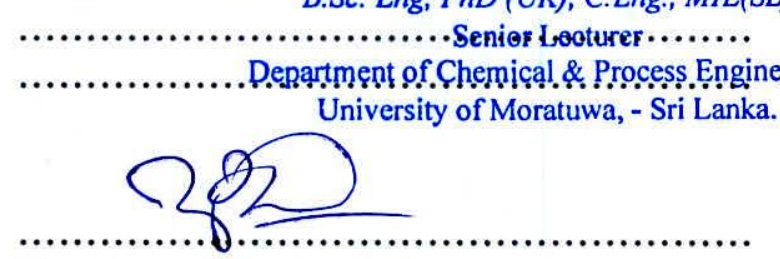

Signature of the supervisor

Dr. N.c. Ganegoda

Name with initials

Name and address

\footnotetext{
-.DEPARTMENT G: MATHEMATIC'S

...University of Sri-jay evardenepura

N...ugegoda

Sri Lanka.
} 


\section{DECLARATION BY THE SUPERVISOR/S}

"I /We certify that the above statement made by the candidate is true and that this thesis is suitable for submission to the University for the purpose of evaluation "

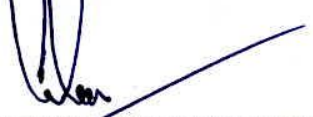

Signature of the supervisor

Name with initials

Name and address

Laken Karunanayake, PhD.

Professor.

Department of Chemistiry

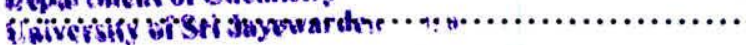

ofthe

Signature of the supervisor

$\bullet$

Name with initials

Name and address

.Dr. Shantha.Walpalage

B.Sc. Eng, PhD (UK), C.Eng.: MIE(SL)

Senior Lecturer

Departmentt of Chemital : $2 \cdot$ Process Engineering

University of Moratuwa, - Sri Lanka.

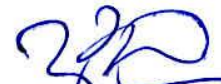

Signature of the supervisor

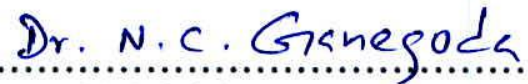

Name with initials

Name and address

..DEPARTMENT. O - MATHEAATTCS

Universtity.of Sri. Jayewardenapura

Nügegoda

*Sritankà: 


\section{TABLE OF CONTENTS}

Table of Contents .................................................................................. i

List of Tables ..................................................................................... vi

List of Figures................................................................................ viii

List of Abbreviations........................................................................ xiii

Acknowledgement........................................................................ xvi

Abstract xviii

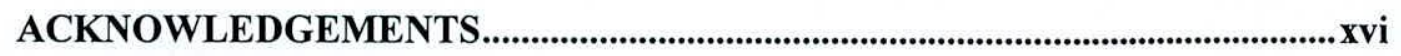

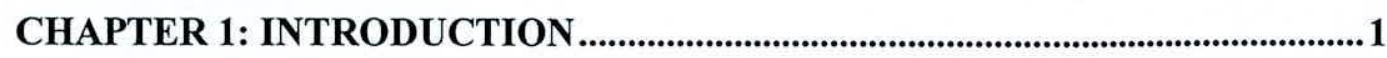

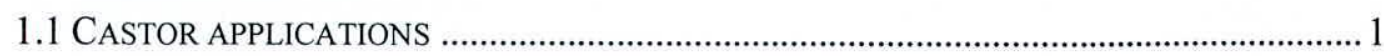

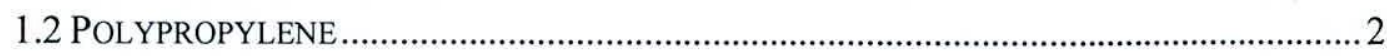

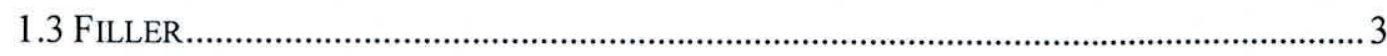

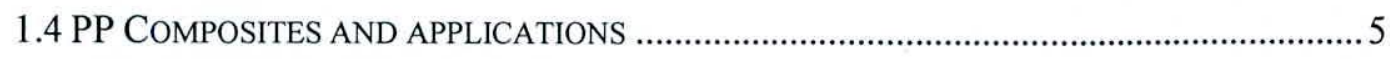

1.5 FINITE ELEMENT ANALYSIS (FEA) OF PP /PP COMPOSITES........................................... 7

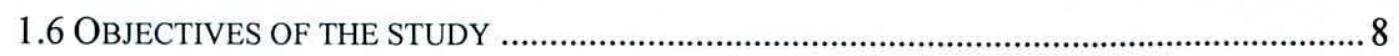

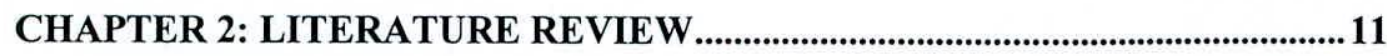

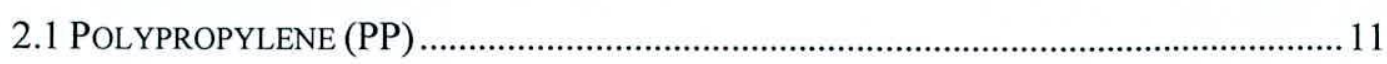

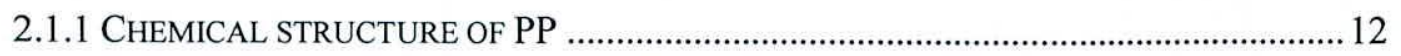

2.1.2 STEREO CHEMICAL CONFIGURATION OF PP (TACTICITY) AND CRYSTALLINE

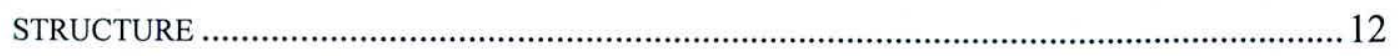

2.1.3 Different types of $P P$................................................................................................... 15

2.1.4 Structure of PP impact copolymer …………………....................................................... 17

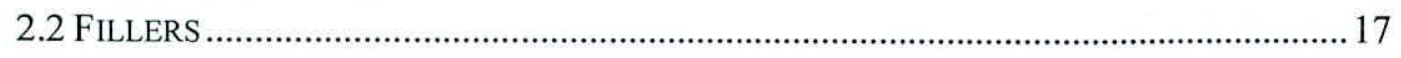

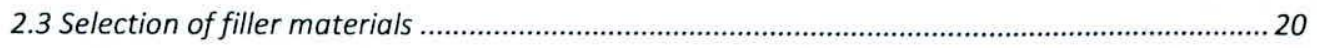

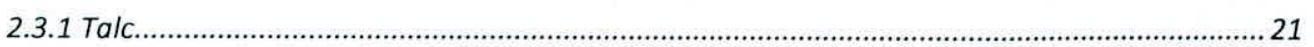


2.3.2 Calcium carbonate

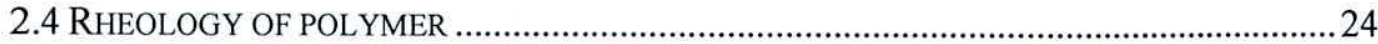

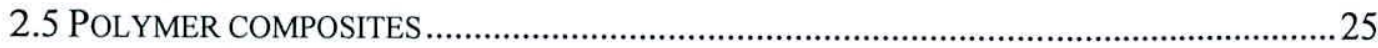

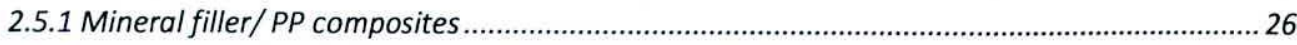

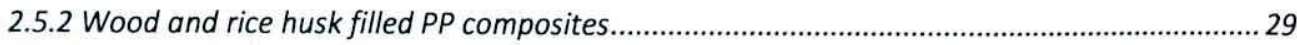

2.6 DYNAMIC MECHANICAL PROPERTIES AND MORPHOLOGY ................................................. 35

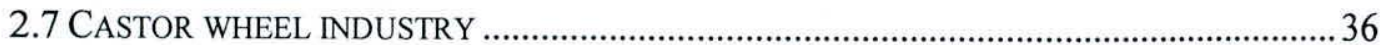

CHAPTER 3: EXPERIMENTAL METHODOLOGY ................................................38

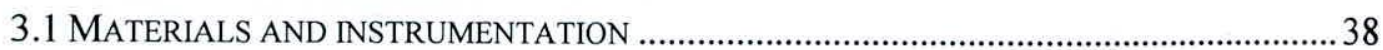

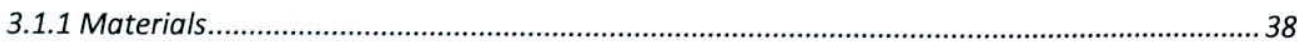

3.1.1.1 POLYPROPYLENE HOMOPOLYMER AND IMPACT COPOLYMER .....................................38

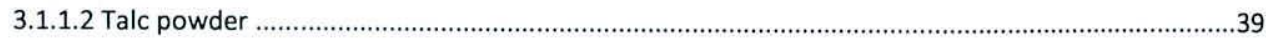

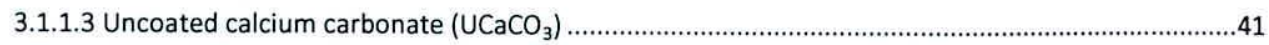

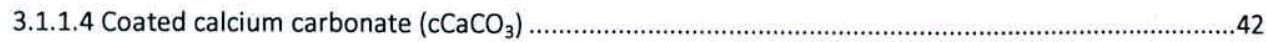

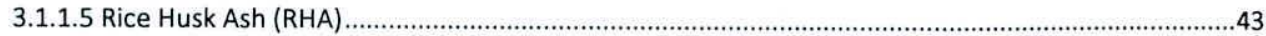

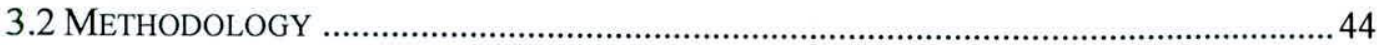

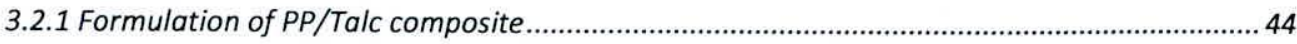

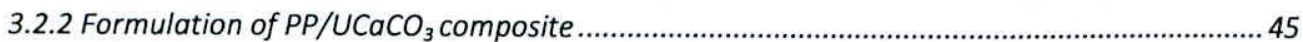

3.2.3 Formulation of $\mathrm{PP} / \mathrm{CCaCO}_{3}$ composite .............................................................................. 46

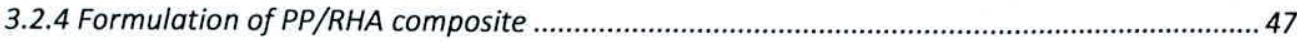

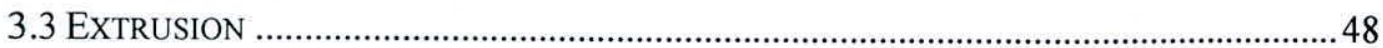

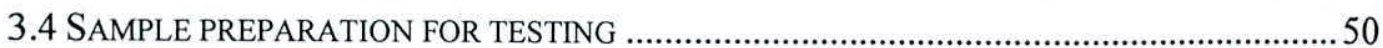

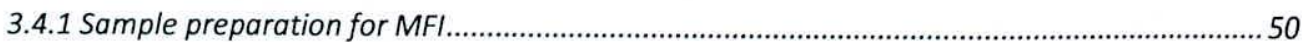

3.4.2 Preparing of Injection moulded test pieces............................................................................... 50

3.4.3 Preparing of injection moulded articles (Castor Wheels)........................................................ 51

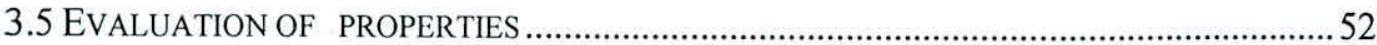


3.5.1 Tensile properties

3.5.2 Impact properties (Izod)

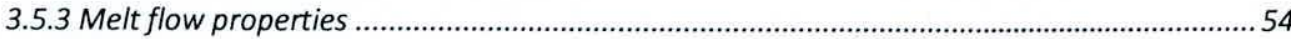

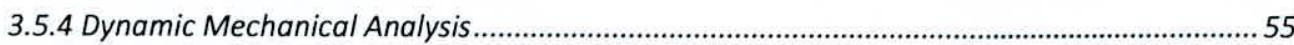

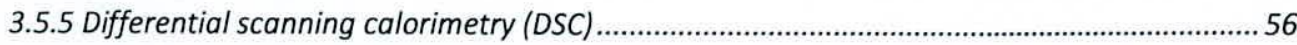

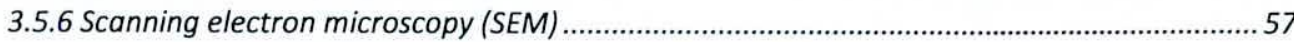

3.5.7 Fourier transform infrared (FTIR) spectroscopy ................................................................. 58

3.5.8 Castor wheel dynamic load and drop weight impact test .................................................... 58

3.6 FINITE ELEMENT STRESS ANALYSIS OF A CASTOR WHEEL (FEA) .................................60

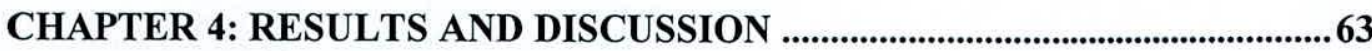

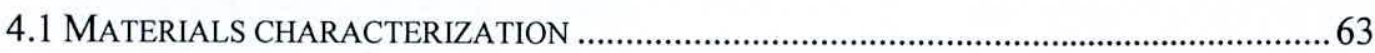

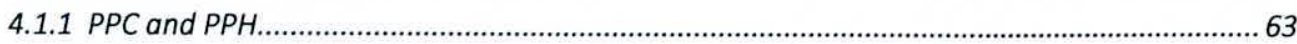

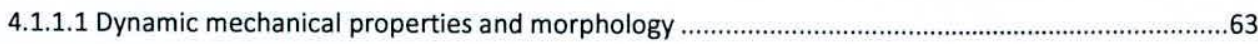

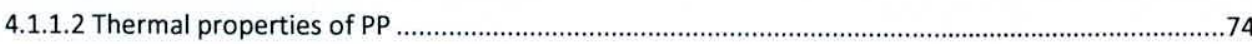

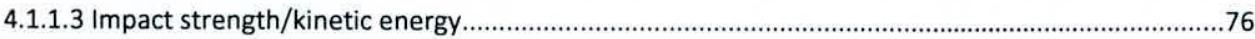

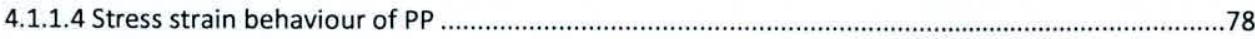

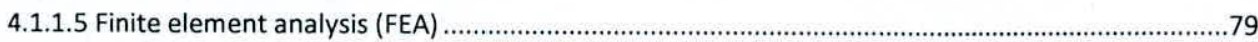

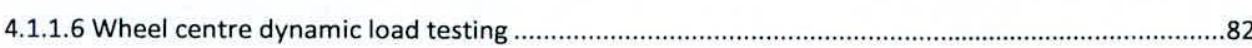

4.1.2 Morphology of filler materials used ( $\mathrm{Talc}_{\mathrm{U}} \mathrm{UCaO}_{3}, \mathrm{UCaCO}_{3}$ and $\mathrm{RHA}$ ).................................... 84

4.1.3 FTIR spectrum of Filler materials used ................................................................................ 88

4.2 PROCESSING AND RHEOLOGICAL PROPERTIES OF PP COMPOSITES ............................... 91

4.2.1 PROCESSING AND MFI OF PP /RHA ….................................................................... 93

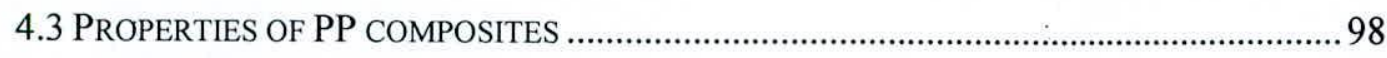

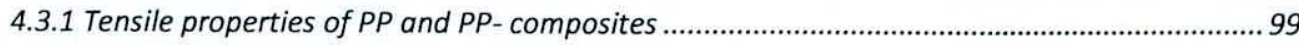

4.3.2 Dynamic mechanical properties of PP composites ................................................................ 106

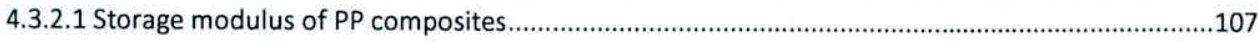

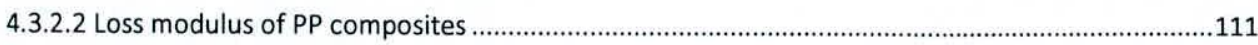

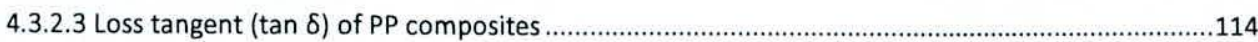


4.3.3 Impact strength of PP composites

4.3.4 PP composites morphology. 126

4.3.5 Thermal properties of PP composites 130

4.3.6 Stress strain behaviour of PP and PP composites 138

4.3.7 Finite element analysis of a castor wheel. 140

4.3.8 Castor wheel dynamic load testing

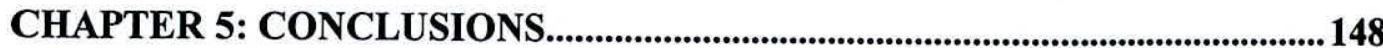

CHAPTER 6: SUGGESTIONS FOR FUTURE WORK 150

REFERENCES: 151 APPENDICES 


\section{LIST OF APPENDICES}

APPENDIX 1: PPC(P640 J) TECHNICAL DATA SHEET ........................................................... 161

APPENDIX 2: PPH (P700) TECHNICAL DATA SHEET ........................................................ 162

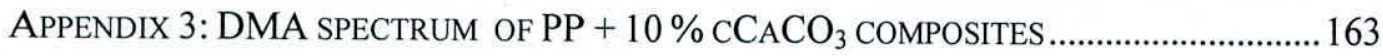

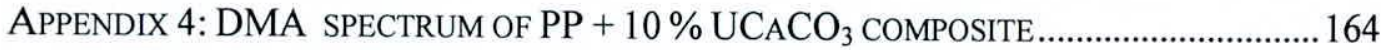

APPENDIX 5: DMA SPECTRUM PP + 10 \% RHA COMPOSITE …......................................... 165

APPENDIX 6: DMA SPECTRUM OF PP + 10 \% TALC COMPOSITE ......................................... 166

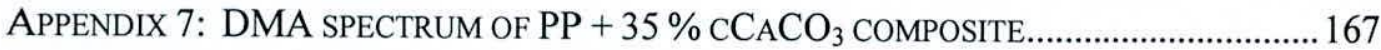

APPENDIX 8: DMA SPECTRUM OF PP + $35 \% \mathrm{UCACO}_{3}$ COMPOSITE ................................ 168

APPENDIX 9: DMA SPECTRUM OF PP + 35 \% TALC COMPOSITE......................................... 169

APPENDIX 10: DSC THERMOGRAMS OF PP + RHA 2.5\% COMPOSITE .............................. 170

APPENDIX 11: DSC THERMOGRAMS OF PP + RHA 5\% COMPOSITE .................................171

APPENDIX 12: DSC THERMOGRAMS OF PP + RHA 7.5\% COMPOSITE .............................. 172

APPENDIX 13: DSC THERMOGRAMS OF PP + RHA 10\% COMPOSITE ............................. 173

APPENDIX 14: DSC THERMOGRAMS OF PP + RHA 12.5\% COMPOSITE ........................... 174

APPENDIX 15: DSC THERMOGRAMS OF PP $+\mathrm{CCACO}_{3}$ 10\% COMPOSITE ........................ 175

APPENDIX 16: DSC GRAPH OF PP + $\mathrm{UCACO}_{3} 10 \%$ COMPOSITE ...................................... 176

APPENDIX 17: DSC THERMOGRAMS OF PP $+\mathrm{CCACO}_{3} 35 \%$ COMPOSITE......................... 177

APPENDIX 18: ChEMICAL COMPOSITIONS OF RiCE HuSK ASH ......................................... 178

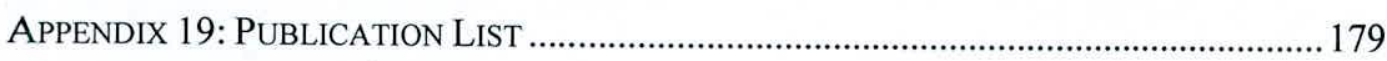




\section{List of Tables}

Table 3.1: Comparison of properties of PPH and PPC (Reference: SCG Plastic) .........39

Table 3.2: Chemical Composition of 325 mesh talc filler materials (Reference: 20

Microns Limited)

Table 3.3: Physical properties of 325 mesh talc filler materials (Reference: 20 Microns

Limited )

Table 3.4: Properties of WT $200 \mathrm{UCaCO}_{3}$ filler material (Reference: Lanka Minerals \&

Chemical)

Table 3.5: Properties of $\mathrm{cCaCO}_{3}$ (Lakcarb $10 \mathrm{C}$ ) filler material (Reference: Lanka

Minerals \& Chemical) 43

Table 3.6: Material weights of PP/Talc composites 45

Table 3.7: Material weights of $\mathrm{PP} / \mathrm{UCaCO}_{3}$ composites 46

Table 3.8: Material weights of $\mathrm{PP} / \mathrm{cCaCO}_{3}$ composites 47

Table 3.9: Material weights of PP/RHA composites 48

Table 3.10: Temperature settings of extruder.

Table 3.11: Injection moulding machine temperature settings. 51

Table 4.1: Comparison of thermal properties of PPC and PPH 76

Table 4.2: Notched izod impact strength at different temperatures [Reference: SCG Plastics] 76

Table 4.3: Kinetic energy given to break the wheel centre at different temperatures ...77 Table 4.4: Maximum stress values of wheel centre of PPH and PPC obtained from FEA

Table 4.5: Chemical Composition of Rice Husk Ash. 86

Table:4.6 particle size and specific gravity of fillers used 87 
Table 4.7: Comparison of Tensile strength and elongation at beak of PP composites with PPCat $5 \%$ and $10 \%$ filler loading 105

Table 4.8: Glass transitions values $\left(\mathrm{T}_{\mathrm{g}}\right)$ of PP composites of RHA, talc, $\mathrm{UCaCO}_{3}$ and $\mathrm{cCaCO}_{3}$ 118

Table 4.9: Thermal properties of PPC and PP composites at $10 \%$ filler loading . 133 Table 4.10: Maximum stress values of castor centre at different PP composites obtained from FEA 142 


\section{List of Figures}

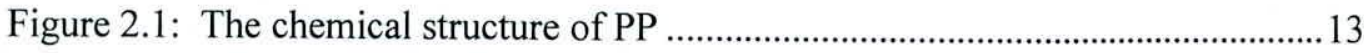

Figure 2.2: Illustration of the stereo chemical configuration of PP...............................13

Figure 2.3: Process flow chart for manufacturing of PP different types(12) ................16

Figure 2.4: Filler, primary particles, Aggregates and Agglomerates.(19)...................... 19

Figure 2.5: Theoretical structure of talc.(17) ..................................................................22

Figure 3.1: Process flow chart of making castor with PP composite ............................44

Figure 3.2: Diagram of the single screw extruder .........................................................49

Figure 3.3: Extrusion of PP composites .......................................................................5

Figure 3.4:Sketch of injection moulding machine temperature Zones..........................51

Figure 3.5: Schematic diagram of a tensile test piece as per ASTM D 638 …...............53

Figure 3.6: Schematic diagram of an izod impact test piece as per ASTM D 256........54

Figure 3.7: Castor wheel dynamic testing machine _.....................................................59

Figure 3.8: Temperature measuring points on the castor wheel centre 3.5.9 Drop weight impact (DWI) testing of castor wheel centre 60

Figure 3.9: 3D model of the castor wheel centre ........................................................... 61

Figure 3.10: Finite element model of $1 / 4$ of castor wheel centre ....................................62

Figure 4.1: DMA spectrum of PPH injection grade (EL - Pro P $700 \mathrm{~J})$........................64

Figure 4.2: DMA spectrum of PPC injection grade (EL - Pro P640 J)..........................64

Figure 4.3: A schematic representation of the formation of PPC.(80) .........................67

Figure 4.4: (a) Conceptual diagram and (b) Scanning Electron microscope of PPC [Reference:http://www.primepolymer.co.jp/english/technology/material/pp/04.h $\mathrm{ml}$

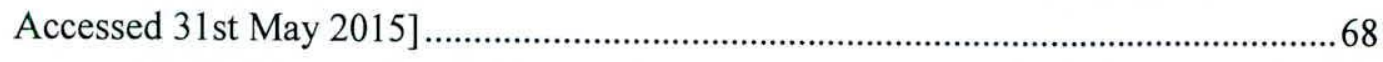

Figure 4.5: SEM image of (a) PPH (EL- Pro P700J) and (b) PP C (EL - Pro P640J)..69 
Figure 4.6: Storage modulus of $\mathrm{PPH}$ and $\mathrm{PPC}$ temperature range -60 to $60{ }^{0} \mathrm{C}$.............71

Figure 4.7:Loss modulus of $\mathrm{PPH}$ and PPC over temperature range -60 to $60{ }^{\circ} \mathrm{C}$.........72

Figure 4.8: Loss Tangent $(\tan \delta)$ over the temperature range of -60 to $60{ }^{0} \mathrm{C}$................73

Figure 4.9: DSC thermograms heating and cooling of $\mathrm{PPH}$ at heating and cooling rate of $10^{\circ} \mathrm{C} / \mathrm{min}$ 75

Figure 4.10: DSC thermograms heating and cooling curves of PPC at heating and cooling rate of $10^{\circ} \mathrm{C} / \mathrm{min}$ .75

Figure 4.11: Failure of wheels centre at the drop weight impact testing. .77

Figure 4.12: Stress and strain behaviour of PPC and PPH at 23 and $60{ }^{\circ} \mathrm{C}$ 79

Figure 4.13: Distribution of stress density obtained from FEA 80

Figure 4.14: Failure of wheel centre at dynamic load application

Figure 4.15: Radar chart of izod impact, yield strength of PPH and PPC and dynamic and drop weight impact load test results.

Figure 4.16: $\mathrm{SEM}$ images of (a) RHA , (b) Talc (c) $\mathrm{cCaCO}_{3}$ (d) $\mathrm{UCaCO}_{3}(\mathrm{X} 1000) \ldots . .85$

Figure 4.17: FTIR Spectrum for (a) $\mathrm{UCaCO}_{3}$ (b) $\mathrm{cCaCO}_{3}$ 89

Figure 4.18: FTIR Spectrum for (a) RHA (b) Talc 90

Figure 4.19: (a) Effects of the filler loading on the MFI (b) Regression graph 94

Figure 4.20: Effects of the filler loading on the MFI (c) PP composites of Talc, $\mathrm{cCaCO}_{3}$ and $\mathrm{UCaCO}_{3}$ regression graph of (d) $\mathrm{PP} /$ Talc (e) $\mathrm{PP} / \mathrm{UCaCO}_{3}$ (f) $\mathrm{PP} / \mathrm{cCaCO}_{3}$ 97

Figure 4.21: Effects of the filler loading on the tensile strength (a) PP composites of Talc, $\mathrm{cCaCO}_{3}$ and $\mathrm{UCaCO}_{3}$ (b) PP composites of RHA 103

Figure 4.22: Effects of the filler loading on the elongation percentage at break 104

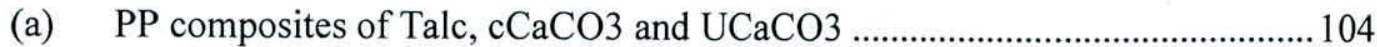

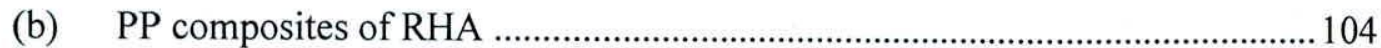


Figure 4.23: Comparison of storage modulus of $\mathrm{PP}$ composites of $\mathrm{UCaCO}_{3} \quad \mathrm{cCaCO}_{3}$,

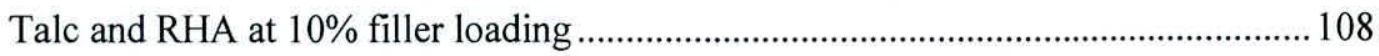

Figure 4.24: Comparison of storage modulus of $\mathrm{PP}$ composites of $\mathrm{UCaCO}_{3} \quad \mathrm{CCaCO}_{3}$ and Talc at $20 \%$ filler loading 109

Figure 4.25: Comparison of storage modulus of PP composites of (a) $\mathrm{UCaCO}_{3}$ and (b) $\mathrm{cCaCO}_{3}$ at $10 \%$ and $35 \%$ filler loading. 110

Figure 4.26: Comparison of loss modulus of PP composites of talc, $\mathrm{cCaCO}_{3}$ and $\mathrm{UCaCO}_{3}$ at $10 \%$ filler loading 112

Figure 4.27: Comparison of loss modulus of PP composites of Talc, $\mathrm{cCaCO}_{3}$ and $\mathrm{UCaCO}_{3}$ at $35 \%$ filler loading

Figure 4.28: Comparison of $\tan \delta$ of PP composites of $\mathrm{RHA}$, Talc, $\mathrm{cCaCO}_{3}$ and $\mathrm{UCaCO}_{3}$ at $10 \%$ filler loading 116

Figure 4.29: Comparison of $\tan \delta$ of PP composites of RHA, Talc, $\mathrm{cCaCO}_{3}$ and $\mathrm{UCaCO}_{3}$ at $35 \%$ filler loading 116

Figure 4.30: Comparison of $\tan \delta$ of PP composites of Talc, $\mathrm{cCaCO}_{3}$ and $\mathrm{UCaCO}_{3}$ at $20 \%$ filler loading 117

Figure 4.31: Comparison of Izod impact strength of PP composites at different filler loading (a) Talc, $\mathrm{UCaCO}_{3}$ and $\mathrm{cCaCO}_{3}$ (b) RHA 121

Figure 4.32: Toughening mechanism of polymer composites with rigid filler particles(56) 124

Figure 4.33: SEM images of (a) PP $+10 \%$ Talc composites (b) PP $+10 \%$ RHA composites

Figure 4.34: SEM images (c) PP + $10 \% \mathrm{UCaCO} 3$ Composite (d) $\mathrm{PP}+10 \% \mathrm{cCaCO} 3$ composites. 128

Figure 4.35: SEM images of PP composites of... 129

(a) $5 \% \mathrm{cCaCO}_{3}$ 129 
(b) $10 \% \mathrm{cCaCO}_{3}$

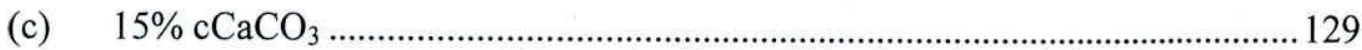

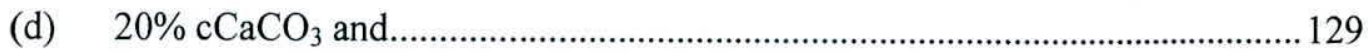

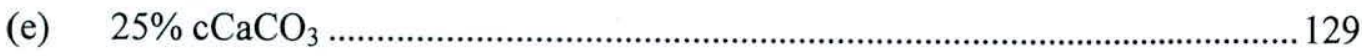

Figure 4.36: Percentage of crystallinity of PP and PP composites at $10 \%$ filler........ 133

Figure 4.37: Exothermic crystallization peaks for PP and PP composites at $10 \%$ filler cooling rate of $10{ }^{\circ} \mathrm{C} / \mathrm{min}$

Figure 4.38: Exothermic crystallization peaks for PP and PP composites of $\mathrm{UCaCO}_{3} \mathrm{CaCO}_{3}$ and cat $35 \%$ filler at cooling rate of $10^{\circ} \mathrm{C} / \mathrm{min}$

Figure 4.39: Crystallization peaks for PP and PP/RHA at different filler loading 136 Figure 4.40: Stress -strain curve of PPC and PP composites at $50 \mathrm{~mm} / \mathrm{min}$ strain at temperature $23^{\circ} \mathrm{C}$

Figure 4.41: Stress -strain curve of selected Virgin PP and PP composites at 50 $\mathrm{mm} / \mathrm{min}$ strain at temperature $60^{\circ} \mathrm{C}$ 140

Figure 4.42: Distribution of stress density obtained from FEA 141

Figure: 4.43 Castor wheels running times at dynamic load test at different filler loading $\%$ 144

Figure: 4.44 Castor wheels running times of different PP composites at dynamic load test. 144

Figure 4.45: Maximum temperature development in the wheel centre at dynamic load failure 146

Figure 4.46: Failure of PP composites wheel centre at the dynamic load test(a) PP +cCaCO3 (b) PP +UCaCO3, (c) PP + RHA (d) PP + Talc 146 


\section{LIST OF ABBREVIATIONS}

ABS

ASTM

ATR

BRHA

$\mathrm{cCaCO}_{3}$

DMA

DSC

EB

EP

EPDM

EPR

FEA

FRH

FTIR

iPP

IPPC

IR

LDPE
Acrylonitrile butadiene styrene copolymer

American society for testing and materials

Attenuated Total Reflection

black rice husk ash

Coated calcium carbonate

Dynamic mechanical analysis

Differential scanning calorimetry

Elongation at break

Ethylene propylene

Ethylene propylene diene monomer

Ethylene propylene rubber

Finite element analysis

Flour rice husk

Fourier transfer infrared spectroscopy

Isotactic polypropylene

Impact polypropylene copolymer

Infrared

Low density polyethylene 
LLDPE

MA

MA-PP

MA-SEBS

MFR

MFI

PE

PPB

$\mathrm{PPH}$

PPC

PP

PS

PVC

PMMA

RHA

SA

SBS

SEM

TPV

$\mathrm{UCaCO}_{3}$

WF
Linear low density polyethylene

Maleic anhydride

Maleic anhydride /PP homopolymer

MA/Styrene- ethylene- butadiene-styrene triblock copolymer

Melt flow rate

Melt flow index

Polyethylene

Block copolymer polypropylene

Polypropylene homopolymer

Polypropylene copolymer

Polypropylene

Polystyrene

Poly vinyl chloride

Poly methyl methacrylate

Rice husk ash

Stearic acid

Styrene butadiene styrene copolymer

Scanning electron microscopy

Thermoplastic vulcanisates

Uncoated calcium carbonate

Wood flour 


$\begin{array}{ll}\text { WRHA } & \text { White rice husk ash } \\ \Delta \mathrm{H}_{-\mathrm{f}} & \text { Enthalpy of PP in composite } \\ \Delta \mathrm{H}_{\mathrm{f}}^{0} & \text { Enthalpy of } 100 \% \text { crystalline PP } \\ \mathrm{W}_{\mathrm{p}} & \text { Weight fraction of PP in composite } \\ \mathrm{T}_{\mathrm{m}} & \text { Melting temperature } \\ \mathrm{T}_{\mathrm{om}} & \text { Onset melting temperature } \\ \mathrm{T}_{\mathrm{oc}} & \text { Onset crystallisation temperature } \\ \mathrm{T}_{\mathrm{c}} & \text { Crystallisation temperature } \\ \mathrm{T}_{\mathrm{g}} & \text { Glass transition temperature } \\ \mathrm{J} / \mathrm{m} & \text { joules per meter } \\ \mathrm{MPa} & \text { Mega pascal } \\ \mathrm{E}^{\prime} & \text { Storage modulus } \\ \mathrm{E}^{\prime \prime} & \text { Loss modulus } \\ \mathrm{Mg}_{3} \mathrm{Si}_{4} \mathrm{O}_{10}(\mathrm{OH})_{2} & \text { Myded magnesium silicat } \\ & \end{array}$




\section{ACKNOWLEDGEMENTS}

I would like to express my deepest gratitude to my supervisors Prof. L. Karunanayake, Department of Chemistry, University of Jayewardenepura Dr. S. Walpalage Department of Chemical Engineering, University of Moratuwa and Dr. N. Ganegoda Department of Mathematics, University of Jayewardenepura for their relentless guidance and unflagging interest shown right throughout my study.

I would like to thank Mr. Bandu Samarasekara, University of Moratuwa, Dr.Nilmini Liyanage, Dr.Upul Rathnayaka, Dr.Sushantha Siriwardena and the staff of Rubber Institute of Sri Lanka, Mr. Chinthana Manoratne of Industrial Technology Institute for their sincere assistance given in testing and analysing data throughout my study.

I also would like to thank the University of Moratuwa, University of Jayewardenepura and Elastomeric Engineering Company limited, Horana, for allowing me to use the facilities available at their polymer laboratories.

I wish to thank the management of Elastomeric Engineering Company limited for giving me an opportunity and freedom to conduct Research study. 
My deep appreciation of the generous gesture of thanks goes out all my friends and colleagues who helped me in numerous ways in the field.

I express my heartfelt gratitude to my loving mother and late farther who guided me along the correct path of education with much sacrifice and dedication.

I owe gratitude to my loving wife Priyadarshani who supported me in every possible way and our sons Dumindu, Savindu and Yuvindu for their patience during this course of study and my family members specially my brother Dr. Kamal Ranatunga for their constant help extended to me in achieving the goal.

Last, but not least, I wish to place on record my gratitude and thanks to staff of Elastomeric Engineering Company limited, too numerous to individually mention, for their assistance and encouragement rendered to me make this a success. 


\title{
A STUDY ON USE OF POLYPROPYLENE (PP) AND PP COMPOSITES IN THE MANUFACTURE OF CASTOR WHEELS AND THEIR EFFECT, ON PROCESSING, DYNAMIC AND STATIC CHARACTERISTICS
}

\author{
Ranatunga Ramanayaka Mudiyanselage Sisira Kumara Ranatunga
}

\begin{abstract}
Present study is to explore the potential of using virgin Polypropylene (PP) materials (PP homopolymer, (PPH) and PP impact copolymer PPC)) and PP composites of rice husk ash (RHA), uncoated $\mathrm{CaCO}_{3}\left(\mathrm{UCaCO}_{3}\right)$ talc and stearic acid coated $\mathrm{CaCO}_{3}$ $\left(\mathrm{cCaCO}_{3}\right)$ for low speed dynamic load applications such as manufacture of light weight castor wheel centre. Industrial grade $\mathrm{PP}$, talc, $\mathrm{UCaCO}_{3}$ and $\mathrm{cCaCO}_{3}$ materials were used for the study. RHA was obtained by uncontrolled combustion of rice husk. Composites of $\mathrm{PP} /$ Talc $\mathrm{PP} / \mathrm{UCaCO}_{3}$, and $\mathrm{PP} / \mathrm{cCaCO}_{3}$ were compounded at $5,10,15,20,25,30$ and $35 \%$ by weight . Composites of PP/RHA were compounded at filler loadings $2.5,5,7.5$, 10 and $12.5 \%$. Extruded pellets of PP and PP composites were tested for melt flow index (MFI). Injection moulded specimens were used for testing tensile strength, izod notched impact strength and dynamic mechanical analysis (DMA). Surface morphology of fillers and PP composites were examined using scanning electron microscopic (SEM) images. Thermal properties of PP and PP composites were studied using differential scanning calorimetry (DSC). Chemical characteristics of filler materials were determined by fourier transform infrared spectroscopy (FTIR). Castor wheel centres were injection moulded to a rubber ring and tested for dynamic load and stress generation using finite element analysis (FEA).
\end{abstract}


As per DSC results, the degree of crystallinity is higher in $\mathrm{PPH}(45 \%)$ compared to PPC (37\%). DMA suggested that PPH is stiffer than PPC which has a multiphase structure. The ethylene propylene rubber (EPR) phase ( $T_{g}$ peak of EPR phase at -35.2 ${ }^{0} \mathrm{C}$ ) which is amorphous in nature provides good impact strength, whereas, matrix made of PP $\left(\mathrm{T}_{\mathrm{g}}\right.$ peak at $\left.15.4{ }^{\circ} \mathrm{C}\right)$ provides stiffness. A shoulder peak of PPC at temperature around $88{ }^{\circ} \mathrm{C}$ has been attributed to the $\alpha$-relaxation in the crystalline phase. Drop weight impact test results suggested that impact property of $\mathrm{PPH}$ is 22 times lower at low temperature compared to that of PPC. Since a balance between impact strength and stiffness is required for optimum performance, PPC is more suitable for light weight dynamic load applications at low temperatures.

PP composites of Talc, RHA and $\mathrm{UCaCO}_{3}$ show significant drop in elongation at break resulting brittle failure. DMA and impact test results suggested that PP composites of RHA, Talc and $\mathrm{uCaCO}_{3}$ have very poor impact properties, whereas, PP composites with $\mathrm{cCaCO}_{3}$ at $20 \%$ prevent $\mathrm{T}_{\alpha}$ transition in the crystalline phase due to lowest stress developed in PP matrix under deformation. The shear yielding bare minimum improving the toughness. PP composite of locally available low cost $\mathrm{cCaCO}_{3}$ is the most suitable material for light-weight dynamic load applications.

Novel FEA model suggested for wheel centre in present study can be applied universally to predict most vulnerable failure area and the stress and displacement of thermoplastic materials at different temperature applications. 